\title{
USO DE TECNOLOGIAS COMPUTACIONAIS NO PROCESSO DE ENSINO E APRENDIZAGEM NAS ESCOLAS PÚBLICAS DO MUNICÍPIO DE PIÚMA
}

\author{
George Bassul Areias, Isaura Alcina Martins Nobre, Marize Lyra Silva Passos \\ Instituto Federal do Espírito Santo \\ Piúma, Espírito Santo \\ E-mail: georgebassul@hotmail.com, isaura@ifes.edu.br,marize@ifes.edu.br
}

\begin{abstract}
Resumo: Este estudo objetivou mapear o uso das tecnologias computacionais na educação nas escolas públicas do ensino fundamental e médio do município de Piúma/ES que faz parte da microrregião Litoral Sul do Espírito Santo, por meio dos objetivos estabelecidos pelo projeto denominado "Observatório da Informática na Educação" do Instituto Federal do Espírito Santo, analisando os aspectos da formação docente no uso das tecnologias computacionais e suas aplicações no processo de ensino e aprendizagem, bem como identificar os recursos tecnológicos disponíveis nos laboratórios de informática; observar algumas aulas que fazem uso dos laboratórios de informática; e apontar desafios e possibilidades quanto ao uso dos recursos computacionais.
\end{abstract}

Palavras-chave: tecnologias computacionais. informática na educação. uso da tecnologia na educação. mediação pedagógica. laboratório de informática.

\section{COMPUTER TECHNOLOGY USE IN PROCESS OF TEACHING IN THE PUBLIC SCHOOLS OF THE CITY OF PIÚMA}

Abstract: This study aimed to map the use of computer technology in education in primary and secondary public schools of the city of Piuma / ES which is part of micro South Coast of the Espirito Santo through the objectives set by the project called "Observatory for Information Technology in Education " of the Instituto Federal do Espirito Santo, analyzing aspects of teacher training in the use of computer technologies and their applications in teaching and learning, and to identify the technological resources available in the computer labs; observe some classes that make use of computer labs; and point out challenges and possibilities in the use of computing resources.

Keywords: computational technologies .information technology in education. use of technology in education. pedagogical mediation. computer lab.

Recebido em 30/09/2015. Publicado em 30/06/2016. 


\section{INTRODUÇÃO}

Com o crescente desenvolvimento das tecnologias especializadas, surgiu a necessidade de se criar alternativas educacionais, buscando criar novas formas de aprendizagem que sejam mais cativantes e motivadoras, considerando que muitos professores são imigrantes digitais se relacionando com nativos digitais. "O uso das tecnologias pode auxiliar o professor a minimizar a indiferença e criar relações estreitas entre docente e discente" (BAZILATTO; JÚNIOR, 2012, p. 108).

Segundo Moran (2012, p.1), "ensinar e aprender exigem hoje muito mais flexibilidade espaçotemporal, pessoal e de grupo, menos conteúdos fixos e processos mais abertos de pesquisa e comunicação." Para tanto, novos processos educativos precisam ser considerados como vias de construção e de transformação, propondo novas estratégias, intervenções e tarefas que possibilitem o desenvolvimento de habilidades e de comportamentos tais como, aprender a aprender, criar e empreender, gerenciar informações, derivar dos resultados de pesquisa novas possibilidades de aplicações no âmbito da atuação profissional, modificar padrões estabelecidos e identificar diferentes possibilidades de atuação social, dentre outros.

Este trabalho teve como objetivo mapear o uso das tecnologias computacionais na educação nas escolas públicas do ensino fundamental e médio do município de Piúma/ES, sendo parte de um projeto maior denominado "Observatório da Informática na Educação" do Instituto Federal do Espírito Santo (Ifes).

\section{USO DE TECNOLOGIAS NA EDUCAÇÃO}

Com o crescente desenvolvimento das tecnologias especializadas, surgiu a necessidade de se criar alternativas educacionais, buscando criar novas formas de aprendizagem que sejam mais aliciantes e motivadoras. O principal desafio vai muito além da elaboração de pressupostos teóricos que sustentem essa flexibilidade sistêmica. Será necessário dar um salto na qualidade do ensino, modificando e renovando o fazer pedagógico, buscando potencializar o mesmo, proporcionando mais recursos e facilidades ao acesso à tecnologia e favorecendo novas perspectivas de inclusão.

Com a modernidade dos recursos, promove-se mais facilmente o acesso ao conhecimento, tornando a educação dinâmica, mas não deixando de desenvolver no sujeito que utiliza tal recurso 
um comportamento responsável e desenvolto para cumprir com organização e autonomia as tarefas pertinentes ao processo de ensino e aprendizagem.

O professor deve ter a capacidade de utilizar os recursos tecnológicos não apenas para preparar suas aulas, mas trabalhar com esses recursos em sala de aula, em prol da aprendizagem dos alunos. As tecnologias contribuem na mudança de paradigmas na educação, alterando o modelo educacional tradicional aplicando novas metodologias de ensino. "[...] Percebemos, também, que em qualquer área do conhecimento, em especial na Educação, leva-se um tempo para apropriação e a adequação das tecnologias disponíveis, que criam um novo e amplo espaço de possibilidades" (CALDAS; NOBRE; GAVA, 2013, p. 15).

As profundas mudanças provocadas pelas tecnologias de informação e comunicação na educação devem ser motivadoras para a capacitação docente, desmistificando e tornando os recursos tecnológicos extensões do professor no ambiente escolar e modernização das aulas. Todos os que estão envolvidos na educação precisam (re)pensar, analisar e planejar ação pedagógicas inovadoras, que evidenciem mudanças e direcionem o fazer docente, motivando e potencializando o ensino por meio de processos permanentes de aprendizagem.

\section{FORMAÇÃO DE PROFESSORES E PRÁTICA REFLEXIVA}

Falar de formação e prática docente significa não só descrever o desempenho da arte de ensinar e educar, mas também destacar e expressar valores, anseios e pretensões que se deseja alcançar e desenvolver na profissão. "[...] É necessária a formação técnica do professor, entretanto, é essencial formar um profissional capaz de realizar mudanças, assumindo conscientemente seu papel de educador" (OLIVEIRA, 2007, p. 47).

Segundo Vasconcellos (1995, p. 67) “[...] o espaço de reflexão crítica e constante sobre a prática é essencial para um trabalho que se quer transformador". Como seres distintos que somos não podendo deixar de lado as nossas diferenças, procurando conhecer variações no processo de aprendizagem para melhorar nosso desempenho como aprendizes, já que, num mundo de constantes e rápidas mudanças, aprender ao longo da vida tornou-se uma necessidade.

Desenvolver habilidades de pensamento e práticas necessárias para o ensino está diretamente ligada as particularidades existentes em cada atividade realizada e em cada indivíduo envolvido 
nesse processo, nos métodos utilizados, na capacidade de controlar e avaliar o trabalho dos discentes e docentes. O professor precisa conhecer essa nova realidade, compreendê-la, e assim, ser atuante.

Segundo Alarcão (1996, apud OLIVEIRA, 2007, p. 44), “[...] para o alcance da prática reflexiva o professor deve ser capaz de organizar uma pedagogia construtivista, criar situações de aprendizagem, experimentar e corrigir, por intermédio do diálogo estabelecido com a sua realidade de trabalho, com a sua atuação".

Dessa forma, ao propor um olhar reflexivo sobre a prática, o professor busca conhecer a realidade na qual está inserido, as formar de intervir, as relações dos saberes teóricos e práticos. O professor quando se propõem a essa postura, inicia uma condição de pesquisador, qualificando o ensinar e o aprender. Na abordagem reflexiva a aprendizagem com a própria experiência é elemento indispensável no desenvolvimento do conhecimento sobre ensino.

\section{MEDIAÇÃO PEDAGÓGICA}

A Educação deve organizar seu processo de ensino e aprendizado nos ambientes escolares, buscando valorização nas relações pessoais e relevância do saber através da práxis cotidiana. Para Demo (2009, p. 17) "ser professor não é dar aula, mas cuidar que o aluno aprenda, bem como ser aluno não é escutar aula, mas reconstruir o conhecimento, formar-se, tornar-se cidadão". O principal desafio vai muito além da elaboração de pressupostos teóricos que sustentem essa flexibilidade sistêmica. Será necessário dar um salto na qualidade do ensino, modificando e renovando o fazer pedagógico, buscando potencializar o ensino, proporcionando mais recursos e facilidades ao acesso à tecnologia e auxiliando novas perspectivas de inclusão social.

Segundo Vercelli (2011, p. 7) “[...] Estamos diante de crianças e jovens que vivem plugados na internet que oferece recursos extremamente motivadores". Desenvolver habilidades de pensamento e práticas necessárias para o ensino está diretamente ligada as particularidades existentes em cada atividade realizada e em cada indivíduo envolvido nesse processo, nos métodos utilizados, na capacidade de controlar e avaliar o trabalho dos discentes e docentes. Quando o aluno percebe a realidade, sua capacidade de inovação e transformação, seus limites são suplantados. 
Embora a didática seja considerada relevante nesse processo de ensino/aprendizagem, os profissionais precisam reconhecer sua importância em todo contexto existente em sua volta, pois é necessário refletir o que se refere o termo ensinar, se a proposta das instituições é que o aluno aprenda apenas o que é proposto pelas ementas ou que seja muito mais sólido, aprendendo de maneira significativa. "[...] A aprendizagem significativa contrapõe a aprendizagem mecânica, que possui pouca ou nenhuma associação a conceitos já existentes na estrutura cognitiva" (VERCELLI, 2011). Assim, a questão não é de apenas o aluno adquirir conhecimento, mas descobrir junto com o professor, mecanismos de aprendizagem através de uma relação pedagógica mediatizada.

A mediação pedagógica refere-se ao relacionamento entre professor e aluno, na busca da aprendizagem como processo de construção do conhecimento. O professor exercer uma postura de facilitador e motivador de processos e conteúdos a serem trabalhados nos ambientes escolares. E, segundo Moran (2000, p. 144) é:

A forma de se apresentar e tratar um conteúdo ou tema que ajuda o aprendiz a coletar informações, relacioná-las, organizá-las, manipulá-las, discuti-las e debatelas com seus colegas, com o professor e com outras pessoas (interaprendizagem), até chegar a produzir um conhecimento que seja significativo para ele, conhecimento que incorpore ao seu mundo intelectual e vivencial e que o ajude a compreender sua realidade humana e social, e mesmo a interferir nela.

Para Vygotsky é a aprendizagem que promove o desenvolvimento, sendo que o desenvolvimento humano se dá de fora para dentro, uma vez que é a partir da cultura manifestada na imersão do sujeito no mundo humano em volta dele, que a aprendizagem aparece, possibilitando definir os rumos do desenvolvimento. A mediação pedagógica se caracteriza através da ação mediatizada do professor, ajudando a desenvolver competências no aluno como motivação, autonomia e o gosto pelo aprender. O professor deve intervir e mediar a relação do aluno com o conhecimento.

\section{METODOLOGIA}

Esta foi uma pesquisa de natureza quantitativa e qualitativa, por meio de estudo de caso, que segundo Lakatos e Marconi (2011, p.276) "refere-se ao levantamento com mais profundidade de determinado caso ou grupo humano sob todos os seus aspectos". 
Areias, Nobre e Passos, 2016 - Tecnologia Educacional

Quanto a natureza, as pesquisas quantitativas e qualitativas oferecem perspectivas diferentes, mas não são necessariamente polos opostos. A abordagem quantitativa é de inspiração positivista e pretende basear-se em dados objetivos passíveis de mensuração. Já a abordagem qualitativa é muita usada no campo das ciências sociais e humanas. Ela é mais adequada para compreensão textual do fenômeno estudado, segue um processo indutivo e não há hipótese a ser comprovada (RAMOS, 2009, p. 184).

Segundo André; Ludke (2013, p. 35) "os focos de observação nas abordagens qualitativas de pesquisa são determinados basicamente pelos propósitos específicos de estudo, que por sua vez derivam de um quadro teórico geral, traçado pelo pesquisador".

Esta pesquisa segundo o seu procedimento técnico foi um estudo de caso que é uma metodológica de investigação especialmente adequada quando procuramos compreender, explorar ou descrever acontecimentos e contextos complexos, nos quais estão simultaneamente envolvidos diversos fatores (Yin, 2005).

Os dados foram levantado com o uso de questionário e entrevistas aplicados a professores e gestores de diversas escolas do município de Piúma-ES. Para análise e interpretação dos dados foram definidas as seguintes categorias para análise: Recursos computacionais disponíveis nas escolas municipais, Formação e atuação de gestores e professores, e Observação da prática docente.

\section{RESULTADOS}

Participaram desta pesquisa 31 professores, o coordenador de informática e o secretário de educação do município. Destes temos que $61,5 \%$ das pessoas entrevistadas são do sexo feminino e 38,5 são do sexo masculino; $72,7 \%$ das pessoas entrevistadas possuem idade acima de 30 anos e não houve participantes com idade abaixo de 25 anos; quanto a jornada de trabalho tem-se que 18,2 trabalham mais de 40 horas semanais, 36,3\% trabalham entre 30 e 40 horas semanais, $27,3 \%$ trabalham de 20 a 30 horas semanais e 18,2\% trabalham até 20 horas semanais, sendo que a grande parte dos professores atuam nos turnos matutinos e vespertinos; $54,5 \%$ dos entrevistados atuam a mais de 5 anos na área educacional, 27,3\% atuam na área num período de 3 a 5 anos e 18,2\% atuam na área de 1 a 3 anos; quanto a formação acadêmica 75\% dos entrevistados 
possuem graduação de nível superior em cursos de Licenciatura e os demais são bacharéis em outras área, tecnólogos ou técnicos; apenas 18,2\% das pessoas entrevistadas possuem formação especifica sobre o uso de tecnologias na educação e $27,3 \%$ dos entrevistados realizam projetos utilizando o laboratório de informática e os recursos computacionais disponíveis.

A partir das observações e entrevistas realizadas foi identificado que o município de Piúma conta com um coordenador de informática, o coordenador possui formação em Nível Superior em Ciências e Especialização em Informática na Educação, o secretário de educação, apresenta formação em nível superior em Enfermagem com especialização em Gestão Municipal. No município os professores utilizam os recursos tecnológicos disponíveis nas escolas para planejar, organizar e conduzir as aulas nos laboratórios de informática. Nenhum projeto é realizado nos laboratórios de informática ou envolvendo as tecnologias de informação e comunicação. Foi também, observado problemas básicos de infraestrutura física dos laboratórios de informática. 0 ambiente não está adequado ao desenvolvimento de projetos educacionais e a utilização de recursos computacionais no processo de ensino e aprendizagem. O uso dos laboratórios é quase que exclusivo para pesquisas na internet e apresentação de trabalhos, não utilizando todo o potencial dos computadores e recursos de informática disponíveis. De acordo com Valente (1999, p.24) "o computador deve ser usado como meio para propiciar a construção do conhecimento".

Considerando os dados obtidos na pesquisa, foi constatado que a grande maioria dos professores possui pouco conhecimento em informática e não recebem capacitação do município e/ou estado para utilização dos recursos computacionais. Muitos professores não sabem, por exemplo, utilizar um software simples como o Power Point ou navegar pela internet. Alguns profissionais buscam aprender por conta própria, justificando que as extensas cargas horárias dificultam a realização de cursos ou capacitações. Segundo Valente $(1998$, p. 139) "dentre os diferentes componentes que contribuem para o desenvolvimento de atividades na área de informática na educação, a formação do profissional capaz de mediar a interação aluno-computador tem sido componente chave". Tal fato corrobora com o pensamento de Alarcão $(1996$, p. 81) quando "[...] os processos de formação implicam o sujeito num processo pessoal, de questionação do saber e da experiência numa atitude de compreensão de si mesmo e do real que o circunda". 
Para um maior aprofundamento na análise quanto à utilização das tecnologias de informação e comunicação como apoio ao processo de ensino e aprendizagem nas escolas foram selecionados dois (02) professores para observação da prática docente. Segundo Reis $(2011$, p. 12) a observação da prática docente "permite aceder, entre outros aspectos, as estratégias e metodologias de ensino utilizadas, as atividades educativas realizadas, ao currículo implementado e as interações estabelecidas entre professores e alunos". Ao selecionar professores e laboratórios foram analisados os questionários virtuais para que a observação não incidisse exclusivamente nos professores em início de carreira ou naqueles com maior dificuldade e para que os laboratórios de informática tivessem condições adequadas de uso.

As aulas foram ministradas em laboratórios de informática, utilizando computadores e acesso à internet. A observação da prática docente buscou mapear o uso da informática na educação, identificando os recursos de informática disponíveis nos laboratórios de informática, as formas do uso dos recursos computacionais pelos docentes como apoio ao processo de ensinoaprendizagem, favorecendo a descoberta de novos conhecimentos e novos ambientes de aprendizagem para alunos do nível fundamental e médio.

Trata-se do desenvolvimento das tecnologias de informação e comunicação, com o uso da internet e do computador, com acesso imediato e em tempo real às informações, ao conhecimento, às experiências e projetos inovadores, com a possibilidade de socialização imediata das pesquisas, com o surgimento, a multiplicação e a diversidade dos aparelhos eletrônicos e games digitais (MORAN, 2013, p. 143).

A primeira prática docente observada foi uma aula de Artes ministrada no laboratório de informática de uma escola municipal para alunos do $6^{\circ}$ ano do ensino fundamental. Nesta aula foi abordado como tema central da aula de artes o dia da Consciência Negra. Em sala de aula aconteceu uma breve explicação sobre o tema e a professora orientou os primeiros passos a serem executados pelos alunos no laboratório de informática.

No laboratório de informática nos deparamos com a ausência do instrutor de informática, o laboratório utilizado possui 24 computadores e como a turma tinha poucos alunos, foi possível trabalhar com um aluno por máquina. Os computadores não ofereciam softwares livres e recursos 
educativos instalados e apresentaram problemas de acesso à internet. Os eventuais problemas de conectividade foram solucionados após análise das configurações de rede e o suporte tecnológico para andamento da aula foi oferecido e conduzido por nós.

Após a solução dos imprevistos, a professora solicitou aos alunos que realizassem uma pesquisa na internet sobre os conceitos e fundamentos envolvendo o tema proposto e desenvolvessem uma síntese utilizando os recursos do editor de texto disponível. Ao finalizarem as primeiras tarefas, a professora realizou uma rápida verificação em cada síntese, orientando e aplicando as correções necessárias. A professora passou a ter uma postura de mediação e seus alunos sujeitos ativos no processo de construção do conhecimento. A professora propôs uma atividade com a perspectiva de construir o conhecimento coletivamente, entre a relação professor-aluno e a relação alunoaluno. Para Vygotsky, essa construção coletiva promove o desenvolvimento intelectual de cada pessoa em dois níveis: real e potencial.

A zona de desenvolvimento proximal é a distância entre o nível de desenvolvimento real, que se costuma determinar através da solução independente de problemas, e o nível de desenvolvimento potencial, determinado através da solução de problemas sob a orientação de um adulto ou em colaboração com companheiros mais capazes (VYGOTSKI, 1991, p. 58).

A segunda parte da aula foi direcionada para utilização de um software educacional. Como o laboratório de informática não oferecia softwares educativos instalados nos computadores, foi necessário buscar recursos similares na internet. Como alternativa, foi trabalhado um Infográfico sobre a origem dos negros e escravização e posteriormente utilizou-se um Quiz sobre a Lei Áurea, o que despertou o interesse e a competitividade dos alunos, considerando que o recurso apresentava um placar ao final da tarefa. A aprendizagem ocorreu de maneira intuitiva e interativa. Segundo Valente (1998, p. 30) "o uso do computador pode enriquecer ambientes de aprendizagem onde o aluno, interagindo com os objetos desse ambiente, tem chance de construir o seu conhecimento".

Os recursos educacionais utilizados ajudaram os alunos a manterem o foco e também a deixá-los em um ambiente onde sentiam-se confortáveis e mais confiantes. O andamento da aula foi mediado pela professora, conduzindo e orientando o fluxo das atividades. Para Vygotsky, o 
professor é figura essencial do saber por representar um elo intermediário entre o aluno e o conhecimento disponível no ambiente. Os objetivos da professora em utilizar os recursos educacionais foram claros. Fixar os conteúdos apresentados em sala de aula e ampliar o conhecimento dos alunos sobre o dia da Consciência Negra. Os recursos utilizados como alternativa na ausência de softwares educacionais específicos foram simples e fáceis de utilizar, atendendo aos objetivos propostos.

A lentidão da conexão com a internet e a falta de recursos didáticos do laboratório de informática foram os principais pontos negativos da aula, e ficou evidente a necessidade de um instrutor de informática, considerando os problemas técnicos que ocorrem no andamento da aula. Os alunos demonstraram conhecimentos básicos de informática e conseguiram realizar as tarefas sem muitas dificuldades. A cooperação entre os alunos foi constante durante toda a aula, e o domínio de sala e conhecimento sobre o tema abordado apresentado pela professora favoreceram o processo de ensino e aprendizagem. A temática foi abordada de forma atraente para os alunos, respeitando os níveis de aprendizagem. De acordo com Moran (1997, p. 4) "é importante que o professor fique atento ao ritmo de cada aluno, às suas formas pessoais de navegação. O professor não impõe; acompanha, sugere, incentiva, questiona, aprende junto com o aluno".

A segunda prática docente observada foi uma aula de História ministrada no laboratório de informática de uma escola estadual para alunos do $2^{\circ}$ ano do ensino médio. Nela, foi abordado como tema central da aula O Brasil no Século XIX - A Proclamação da República. Em sala de aula aconteceu uma breve explicação sobre o tema e foram direcionados os primeiros comandos a serem executados pelos alunos no laboratório de informática.

O laboratório utilizado possui 18 computadores. O quantitativo de máquinas atendeu a demanda de 33 alunos, considerando que foram criados grupos de 3 alunos. Os computadores não ofereciam softwares livres e recursos educativos instalados e apresentaram lentidão no acesso à internet. O instrutor de informática apresentava pouco domínio técnico e limitação no auxílio e organização da aula.

O professor solicitou aos alunos que realizassem uma pesquisa na internet sobre os conceitos e fundamentos envolvendo o tema proposto e desenvolvessem uma apresentação utilizando os recursos do programa para criação e exibição de apresentações gráficas instalado nos 
computadores. A atividade foi orientada e supervisionada pelo professor. $\mathrm{O}$ instrutor de informática se manteve omisso durante a maior parte do processo de desenvolvimento das apresentações. Considerando o objetivo final da atividade, a internet favoreceu o processo de elaboração e desenvolvimento da apresentação pela ampla variedade de conteúdo disponível, possibilitando aos alunos apresentarem conteúdos interessantes e relevantes. Conforme Moran $(1997$, p. 5) "uma das características mais interessantes da Internet é a possibilidade de descobrir lugares inesperados, de encontrar materiais valiosos, endereços curiosos, programas úteis, pessoas divertidas, informações relevantes".

A aprendizagem ocorreu de maneira interativa. Como o objetivo final seria a apresentação das atividades desenvolvidas pelos grupos, os alunos mantiveram-se focados na atividade. O professor se manteve presente buscando tornar o ambiente confortável para os alunos. A lentidão da conexão com a internet e a falta de recursos didáticos do laboratório de informática foram os principais pontos negativos da aula, ficando evidente a necessidade de um instrutor de informática mais participativo. Os alunos demonstraram conhecimentos básicos de informática e conseguiram realizar as tarefas, entretanto com algumas dificuldades. O professor apresentou excelente domínio de sala, conhecimento sobre o tema abordado e facilidade em utilizar os recursos computacionais.

Apesar das observações terem ocorridos em escolas díspares e com professores de disciplinas e formações distintas, as temáticas utilizadas por ambos foram convergentes, apresentando situações e práticas docente similares. Foi possível identificar um anseio por parte dos alunos ao se depararem com os recursos computacionais disponíveis nos laboratórios e uma tensão dos professores em relação ao resultado final daquelas aulas.

Criar, estruturar e dinamizar situações de aprendizagem e estimular a aprendizagem e a autoconfiança nas capacidades individuais para aprender são competências que o professor de hoje tem de desenvolver. [...] O grande desafio para os professores vai ser ajudar a desenvolver nos alunos, futuros cidadãos, a capacidade de trabalho autônomo e colaborativo, mas também o espírito crítico (ALARCÃO, 2008, p.32-34). 
Ao conversar com alguns alunos, foi possível constatar que também carecem de capacitação e motivação para tornarem os recursos computacionais parte do seu cotidiano de aprendizagem. Os alunos relataram problemas com infraestrutura física, nos quais foram comprovados através das pesquisas realizadas e visitas in loco, e relatam que o pouco conhecimento técnico ou ausência dos instrutores de informática dificultam o andamento das aulas e fazem o contato com o computador não ser prazeroso. As tecnologias não são usadas de um modo significativo para o aluno, tornando-o apenas expectador do processo educativo, processo pelo qual deveria ser sujeito ativo, onde os conteúdos e práticas são apresentados como "retalhos da realidade, desconectados da totalidade em que se engendram e em cuja visão ganharia significação" (FREIRE, 1997, p. 57).

Fiel a objetivos específicos que contemplam o projeto, considerando a observação de algumas aulas e o apontamento de desafios e possibilidades quanto ao uso de recursos computacionais, foi necessário criar um clima e uma cultura em que a parceria no desenvolvimento profissional estivesse acima de melindres pessoais. Os professores foram envolvidos no processo de planejamento das observações e tiveram acesso às planilhas de controle utilizadas, diminuindo a ansiedade e quebrando as possíveis resistências. Ao final das aulas foi possível pontuar as vertentes positivas e os processos didáticos que poderiam ser melhorados ao utilizar recursos computacionais.

Os professores relataram a importância de desenvolverem mecanismos que auxiliem suas aulas e sabem da necessidade de estarem em constante contato com as tecnologias e mídias, não podendo se limitar apenas a quadros e aulas expositivas. As dificuldades ao se relacionarem com os recursos computacionais são evidentes, mas justificadas pela deficiência na formação profissional e continuada, a falta de tempo pela extensa carga horária, a acomodação de alguns profissionais, além do pouco incentivo para se aprimorarem e a precária infraestrutura dos laboratórios de informática.

As observações das práticas docentes constituíram um processo colaborativo entre observador, professores e alunos, de forma a assegurar benefícios mútuos no desenvolvimento educativo, com o propósito de direcionar a aprendizagem, organizando e estruturando os conteúdos apresentados, não realizando um processo mecânico, mas sim com atividades significativas por 
meio de vertentes instrucionistas e construcionistas. O aluno não deve ser apenas instruído e ensinado, mas também é necessário ser o construtor do seu próprio conhecimento. Segundo Valente:

[...] existem diversas maneiras de usar o computador na educação. Uma maneira é informatizando os métodos tradicionais de instrução. Do ponto de vista pedagógico, esse seria paradigma instrucionista. No entanto, o computador pode enriquecer ambientes de aprendizagem onde o aluno, interagindo com os objetos desse ambiente, tem chance de construir o seu conhecimento. Nesse caso, o conhecimento não é passado para o aluno. O aluno não é mais instruído, ensinado, mas é o construtor do seu próprio conhecimento. Esse é o paradigma construicionista onde a ênfase está na aprendizagem ao invés de estar no ensino; na construção do conhecimento e não na instrução (VALENTE, 1999, p. 24-25).

O conhecimento deve oportunizar a articulação entre teoria vista em sala e prática cotidiana, levando os alunos a entenderem a necessidade de se tornarem cidadãos mais críticos, reflexivos, conscientes, participativos e principalmente responsáveis pela sociedade e comunidade escolar.

\section{ASPECTOS CONCLUSIVOS}

O ambiente de aprendizagem computacional constitui-se um espaço aberto à construção do conhecimento, à construção cognitiva, sócio-afetiva da interação e comunicação entre alunos e educadores. Ao mapear o uso da informática na educação, observando e refletindo sobre o uso das tecnologias computacionais como apoio ao processo de ensino-aprendizagem nas escolas públicas situadas no município de Piúma/ES, foi constatado que em sua totalidade não são utilizados apropriadamente processos tecnológicos aplicados aos métodos de ensino, que proporcionariam conceitos mais próximos da realidade social.

A ausência de uma interface dessa natureza faz do ensino algo estático e restrito à sala de aula. As abrangências tecnológicas nem sempre são amplamente dominadas ou exploradas pelos professores. Para ampliar as possibilidades de conhecimento, é necessário que recursos tecnológicos sejam alinhados ao processo de ensino, principalmente ao sujeito que irá vivenciar novas experiências e práticas através da inserção de ambientes educativos não formais em seu contexto escolar. 
Por meio da análise de dados observamos que o cenário da estrutura física dos espaços dos laboratórios de informática e da sua efetiva utilização no cotidiano das escolas realçou contrastes de problemas técnicos, de infraestrutura e humanos. É preocupante o fato de que na maioria das escolas visitadas não havia profissionais habilitados que pudessem articular o funcionamento do laboratório no cotidiano escolar, auxiliando os professores e alunos quanto ao uso das tecnologias. Aos professores fica o anseio de que o município e o estado garantam investimentos em infraestrutura física e suporte especializado, e ofertem cursos e treinamentos que possam possibilitar condições do uso efetivo dos recursos computacionais. Existe um grande número de professores que precisam de treinamento, todavia, não é possível dizer que as escolas estão preparadas em termos de infraestrutura para que o professor possam colocar em prática tudo o que sabem ou irão aprender nas capacitações.

Assim, não basta apenas equipar as escolas com laboratórios e recursos computacionais, mas potencializar o desenvolvimento de ações originadas no âmbito de cada realidade escolar de modo a envolver e articular todas as pessoas intrincadas nos processos educacionais.

\section{REFERÊNCIAS}

ALARCÃO, Isabel (org.). Formação reflexiva de professores: estratégia de supervisão. Portugal: Porto Editora, 1996.

ALARCÃO, Isabel. Professores Reflexivos em uma escola reflexiva. 6. ed. São Paulo: Cortez, 2008.

BAZILATTO, Alexandre; JÚNIOR, José Renato Giuberti. Comunicação, afetividade e tecnologias educacionais no processo de ensino e aprendizagem. Vitória, ES: Instituto Federal de Educação, Ciência e Tecnologia do Espírito Santo, 2012.

CALDAS, Wagner K.; NOBRE, Isaura A. M.; GAVA, Tânia B. S. Uso do computador na educação: Desafios Tecnológicos e pedagógicos. Informática na Educação - Um caminho de possibilidades e desafios. Serra, ES: Instituto Federal de Educação, Ciência e Tecnologia do Espírito Santo, 2013.

DEMO, Pedro. Educação Hoje: Novas Tecnologias, Pressões e Oportunidades. São Paulo: Atlas, 2009.

FREIRE, Paulo. Pedagogia da autonomia: saberes necessários à prática educativa. São Paulo: Paz e Terra, 1997 .

LAKATOS, Eva Maria; MARCONI, Marina de Andrade. Metodologia Científica. 6o. Ed. São Paulo: Atlas, 2011.

LÜDKE, Menga e ANDRÉ, Marli E. D. A. Pesquisa em educação: abordagens qualitativas. 2ạ. Ed. São Paulo: EPU, 2013.

MORAN, José Manuel. Como utilizar a internet na educação. Publicado em 1997. Disponível em: <scielo.br/scielo.php?pid=s0100-19651997000200006\&script=sci_arttext>. Acesso em: 15 mar. 2015. 
MORAN, José M. MASETTO, Marcos. T.; BEHRENS, Marilda. A. Novas tecnologias e mediação pedagógica. Campinas: Papirus, 2000.

MORAN, José M. MASETTO, Marcos. T.; BEHRENS, Marilda. A. Novas tecnologias e mediação pedagógica. Campinas: Papirus, 2013.

MORAN, José M. O Uso das Novas Tecnologias da Informação e da Comunicação na EAD - uma leitura crítica dos meios. Universidade de São Paulo. 2012. Disponível em: <portal.mec.gov.br/seed/arquivos/pdf/T6\%20Texto Moran.pdf>. Acesso em: 21 out. 2014.

OLIVEIRA, Ana Maria Rocha. A contribuição da prática reflexiva para uma docência com profissionalidade. Rio de Janeiro: Senac, 2007. Disponível em: <senac.br/BTS/331/artigo 04.pdf>. Acesso em: 26 out. 2014.

RAMOS, Albenides. Metodologia da Pesquisa Científica. São Paulo: Atlas, 2009.

REIS, Edna dos. Aprendizagem e docência digital. Em: NOBRE, Isaura Alcina M. et al. Informática na educação: um caminho de possibilidades e desafios. Serra, ES: Instituto Federal de Educação, Ciência e Tecnologia do Espírito Santo, 2011.

VALENTE, José Armando. Computadores e conhecimento: repensando a educação. 2ạ edição. Campinas, SP: Unicamp/NIED. 1998.

VALENTE, José Armando. O computador na sociedade do conhecimento. Campinas, SP: Nied, 1999.

VASCONCELLOS, Celso dos Santos. Construção do conhecimento em sala de aula. São Paulo: Libertad, 1995.

VERCELLI, Ligia de Carvalho A. Estação Ciência: Espaço educativo institucional não formal de aprendizagem. Anais do IV encontro de Pesquisa Discente do Programa de Pós-Graduação em Educação da UNINOVE, 2011.

VYGOTSKI, Lev Semyonovitch. A formação social da mente. 4a ed. São Paulo: Martins Fontes, 1991.

YIN, R. K. Estudo de caso: planejamento e métodos. 3a ed. Porto Alegre: Bookman, 2005. 